УДК 541.6: 662.8

\title{
The Use of Binders from Sawdust \\ and Biomodified Brown Coal \\ for Obtaining the Fuel Briquettes
}

\author{
Ivan P. Ivanov and Nikolay V. Chesnokov* \\ Institute of Chemistry and Chemical Technology SB RAS \\ 50/24 Academgorodok, Krasnoyarsk, 660036, Russia
}

Received 09.06.2015, received in revised form 23.07.2015, accepted 03.08.2015

The use of binders from sawdust, biomodified brown coal and their mixtures makes possible to obtain fuel briquettes with a compressive strength 7-9 MPa at specific pressures 100-140 MPa. The strength of obtained briquettes depends on a nature and composition of the binders used.

It was found that the calorific value and the duration of a briquetted fuel combustion are increasing with the increase of biocoal content in briquetted blend.

Keywords: brown coal, binders, sawdust, biocoal, briquettes.

DOI: $10.17516 / 1998-2836-2015-8-3-430-438$.

\section{Использование связующих}

на основе древесных опилок

и биомодифицированного бурого угля

для получения топливных брикетов

И.П. Иванов, Н.В. Чесноков

Институт химии и химической технологии СО РАН Россия, 660036, Красноярск, Академгородок, 50/24

Использование в качестве связуюших древесных опилок, биоуглей и их смесей позволяет получать топливные брикеты с прочностью на сжатие 7-9 МПа при удельных давлениях прессования 100-140 МПа. Прочность получаемых брикетов зависит от природы состава

(C) Siberian Federal University. All rights reserved

* Corresponding author E-mail address: ivanov@icct.ru 
связующего. Показано, что теплотворная способность и продолжительность процесса горения брикетов возрастают при увеличении содержания биоугля в брикетируемой шихте.

Ключевые слова: бурый уголь, связующее, древесные опилки, биоуголь, брикетыл.

\section{Введение}

Бурые угли Канско-Ачинского угольного бассейна (КАБа), промышленные запасы которых оцениваются в 115 млрд т, характеризуются низкой зольностью, незначительным содержанием серы и азота, а также низкой себестоимостью, обусловленной открытым способом добычи из мощных пластов [1]. Между тем при их добыче открытым способом происходит разубоживание угля и образуется до 15 \% класса крупности 0-6 мм и до 30 \% класса 0-13 мм, непригодных для слоевого сжигания.

Основными причинами, определяющими целесообразность получения из бурых углей брикетированного твердого топлива, являются их высокая влажность, возможность самовозгорания при хранении, а также значительные потери при транспортировке.

Однако до настоящего времени не было реализовано ни одного промышленного брикетного производства на основе бурых углей КАБа, относящихся к группе Б2-Б3 . Это связано с тем, что эти угли не обладают пластичностью, необходимой для получения прочных брикетов [2], а также отсутствием прессового оборудования, развивающего удельные давления прессования более $180 \mathrm{M \Pi а.}$

Повышение пластических свойств бурых углей и снижение удельных давлений прессования до уровня 100-140 МПа возможно путем введения в брикетируемую шихту связующего [3]. Помимо хороших пластических свойств связующее должно быть недефицитным и не ухудшать энергетических характеристик топливных брикетов.

Одним из таких связующих могут быть древесные отходы, образующиеся в значительных количествах в процессе заготовки и переработки древесины. Отходы древесины широко используются при производстве топливных пеллет и брикетов [4].

Проведенными ранее исследованиями было показано, что продукты аэробной биопереработки бурых углей (биоугли) проявляют связующую активность при брикетировании [5]. Введение в шихту для брикетирования углей Б2-Б3 в качестве связующих биообработанных углей (биоуглей) позволяет получать прочное высококалорийное топливо [6].

Наличие связующих свойств у биоуглей связано с увеличением содержания гуминовых кислот в продуктах биопереработки по сравнению с исходным углем. При этом происходит образование большого количества полярных функциональных групп, повышающих пластические свойства угольной шихты и генерацию связующих свойств [7].

Исследования [8] показали, что аэробная биопереработка бурого угля штаммом бактерий Acinetobacter calcoaceticus приводит к увеличению содержания кислорода в биомодифицированных бурых углях и сопровождается повышением выхода гуминовых кислот до 32,8 мас.\% по сравнению с исходным бурым углем (выход гуминовых кислот 24,77 мас.\%).

Актуальна задача расширения сырьевой базы для получения связующих, в частности использование в качестве связующих веществ древесных отходов (опилок) и продуктов микробиологической переработки бурого угля.

$$
-431-
$$


Целью данного исследования было изучение возможности использования связующих из древесных опилок, биообработанных бурых углей и их смесей при брикетировании березовского бурого угля КАБа.

\section{Экспериментальная часть}

В качестве исходного сырья для брикетирования использовали отсев бурого угля Березовского месторождения КАБа и древесные опилки смешанного состава. Петрографический состав исходного березовского угля, \%: $\mathrm{Vt}-93,1 ; \mathrm{Sv}-3,0 ; \mathrm{F}-2,3 ; \mathrm{L}-1,6 ; \mathrm{R}-0,36$. Выход летучих $47,4 \%$, рабочая теплота сгорания угля 14,7 МДж/кг. Для брикетирования использовали фракцию угля 0-3 мм с диапазоном влажности 10-22 мас.\%.

Сушку бурого угля с исходной влажностью 29 мас.\% производили на лотках в термошкафу СНОЛ при температуре $85-90{ }^{\circ} \mathrm{C}$. Влажность контролировали путем периодического отбора проб. По достижении требуемой влажности сушку угля прекращали, а высушенный уголь помещали в герметичную тару.

Биообработку бурого угля крупностью 0-1 мм проводили в аэробных условиях с использованием штамма микроорганизмов Acinetobacter calcoaceticus BКПM B-4833. Продолжительность процесса биопереработки составляла 20 ч.

Биосвязующее (БС), используемое при брикетировании бурого угля, получали путем предварительной сушки биоугольных суспензий с исходной влажностью 65-70 \% на противнях при температуре $55-60{ }^{\circ} \mathrm{C}$ до остаточной влажности $22-24 \%$.

Высушенные до влажности 22-24 \% БС измельчали до крупности 0-0,30 мм. Подготовленные образцы подвергали дополнительной сушке до влажности 6-20 мас.\%. Контроль содержания влаги в БС производили, как и в случае сушки угля, периодическим отбором проб.

В качестве связующего при брикетировании бурого угля использовали опилки смешанных пород древесины класса крупности 0-2,5 мм и диапазона влажности 5-20 мас.\%.

Опилки с исходной влажностью 44 мас.\% подвергали сушке при температуре $60{ }^{\circ} \mathrm{C}$ в сушильном шкафу с принудительной вентиляцией. Контроль влажности производили путем периодического отбора проб на анализ. По достижении требуемой влажности сушку прекращали, а высушенные опилки помещали в герметичную тару.

Влажность опилок, исходных и биопереработанных бурых углей определяли по ГОСТ 26713-85.

Прессование подготовленных материалов проводили на гидравлическом прессе МC-500. Удельное давление прессования варьировали от 100 до 140 МПа. Контроль давления прессования производили по двухшкальному динамометру.

Для брикетирования использовали цилиндрические пресс-формы диаметром 50 мм. Вес брикета (навески) составлял 50 г, высота брикетов 25 мм.

Получаемые брикеты подвергали испытаниям по прочности на сжатие через 4 и 24 ч согласно ГОСТ 21189-21191-75. Определение теплотворной способности и элементный состав проводили согласно СТ СЭВ 1463-78.

Испытание полученных брикетов по прочности при сжигании определяли по методикам, приведенным в работе [9]. Проведение испытаний проводили с брикетами через 24 ч после их изготовления. 
Таблица 1. Характеристика используемого сырья

\begin{tabular}{|c|c|c|c|c|c|c|c|c|c|}
\hline \multirow{2}{*}{$\begin{array}{l}\text { №, } \\
\text { п/п }\end{array}$} & \multirow{2}{*}{ Исходное сырье } & \multicolumn{7}{|c|}{ Элементный и технический состав, \% } & \multirow{2}{*}{$\begin{array}{c}\text { Tеплота сгорания } \\
\mathrm{Q}_{\mathrm{s}}^{\text {daf }} \text {, ккал/кг }\end{array}$} \\
\hline & & $\mathrm{W}^{\mathrm{r}}$ & $\mathrm{A}^{\mathrm{d}}$ & $\mathrm{C}^{\mathrm{daf}}$ & $\mathrm{H}^{\mathrm{daf}}$ & $\mathrm{S}^{\mathrm{daf}}$ & $\mathrm{N}^{\text {daf }}$ & $\mathrm{O}^{\mathrm{d}}$ & \\
\hline 1 & Бурый уголь & 33,0 & 5,1 & 72,9 & 4,4 & 0,18 & 0,85 & 22,57 & 6858 \\
\hline 2 & Древесные опилки & 43,0 & 1,0 & 52,6 & 6,3 & 0,05 & 0,07 & 40,07 & 4735 \\
\hline 3 & Биоугольная суспензия & 68,0 & 7,4 & 70,9 & 4,4 & 0,24 & 0,78 & 23,90 & 6683 \\
\hline
\end{tabular}

Элементный и технический состав исходного сырья приведен в табл. 1.

\section{Результаты и обсуждение}

Низкие пластические свойства бурых углей группы Б2 не позволяют получать прочные брикеты (прочность на сжатие 7-9 МПа) при удельном давлении прессования 100-120 МПа, развиваемых промышленными штемпельными прессами.

При получении буроугольных брикетов имеется существенное различие в величине энергии, затрачиваемой на прессование при изготовлении брикетов, в сравнении с величиной энергии, необходимой для их деформации [10]. Так, для возникновения дисперсионных сил сцепления необходимо приложить усилие в 20 МПа, а водородных связей - около 50-200 МПа. Это различие в величинах энергии образования сил взаимодействия связано не только с преодолением сил упругости, но и со следующими факторами:

- малым коэффициентом использования энергии непосредственно на образование сил взаимодействия - большая часть энергии расходуется на внешнее (в прессах) и внутреннее (между частицами) трение;

- с увеличением объема прессуемой угольной шихты возрастают пространственные затруднения, что связано с неравномерностью передачи накладываемого усилия по толщине слоя брикета.

Эти факторы являются препятствием к снижению затрат энергии на образование прочных брикетов и полного теоретически возможного использования сил взаимодействия в заданном объеме брикета. При этом основной метод, направленный на снижение влияния указанных выше факторов на процесс брикетирования, заключается в придании прессуемой шихте достаточных пластических свойств или введении пластифицирующих добавок.

Пластичность, в свою очередь, обусловлена внутренним трением частиц угольной шихты и связующего, их адгезионными и когезионными свойствами и т.д. Поэтому качество получаемых брикетов будет зависеть от количества вводимого связующего, его влажности, температуры и давления прессования, гранулометрического состава и формы зерен и ряда других факторов, влияющих на процесс прессования при получении брикетов [11].

Изучение пластических свойств древесных опилок при прессовании показало, что они обладают высокими пластическими свойствами. Представленные на рис. 1 зависимости прочности на сжатие брикетов из опилок от их влажности свидетельствуют о том, что при давлении прессования 100 МПа максимальная прочность брикетов на сжатие (43 МПа через 4 ч) соответствует интервалу влажности опилок 8,0-9,0 мас. \%.

$$
-433-
$$


Испытания прочности брикетов через 24 ч свидетельствуют о том, что их прочность снижается на 11,3 отн. \% (до 37 МПа). Данный факт может быть охарактеризован процессами релаксации древесных волокон после снятия давления, а также некоторым увеличением влажности брикетов (до 8,5-9,0 мас. \%).

Исследование прочностных свойств брикетов, полученных при прессовании шихты, состоящей из 60 мас. \% березовского бурого угля и 40 мас. \% опилок различной влажности, показывает, что максимум прочности брикетов (33,5 МПа) достигается при влажности опилок около 9 мас. \% и влажности угля около 17 мас. \% (рис. 2). Испытания прочности брикетов, проведенные через 24 ч, выявили, что их прочность снижается на 14,1 отн. \% (до 28,8 МПа).

При использовании в качестве связующего вещества древесных отходов могут возникнуть проблемы, связанные с их дефицитом, а также высокой стоимостью доставки.

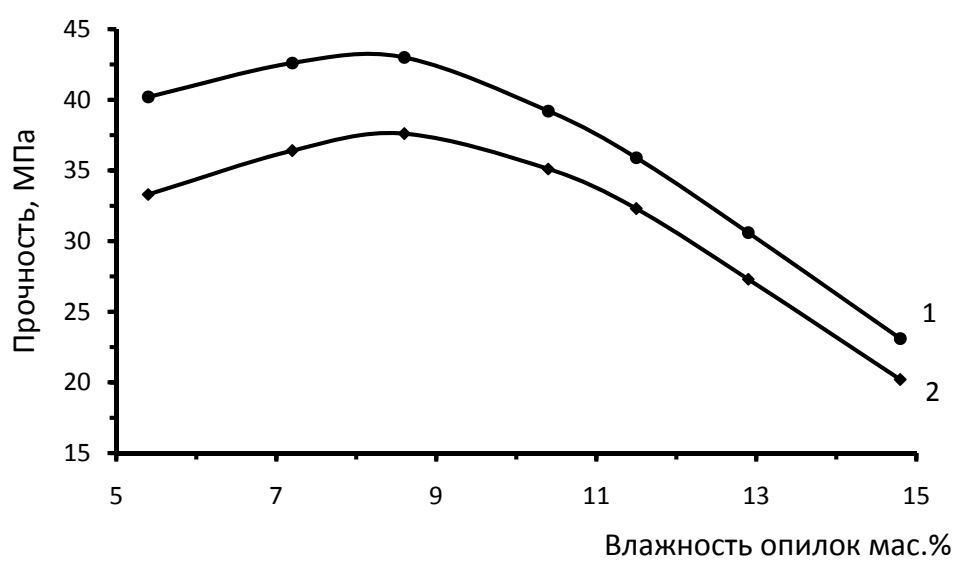

Рис. 1. Влияние влажности древесных опилок на прочность полученных брикетов: 1 - прочность через 4 ч; 2 - прочность через 24 ч

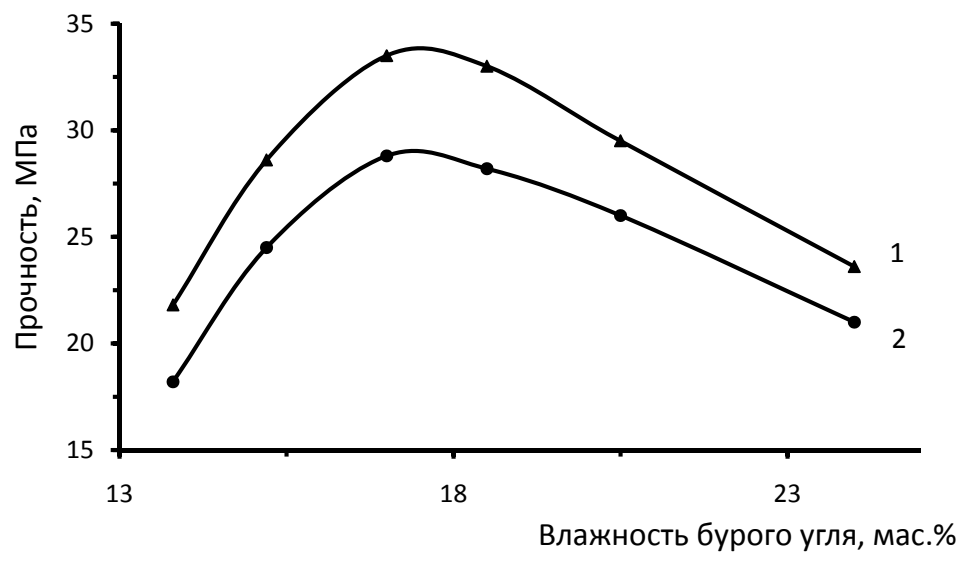

Рис. 2. Зависимость прочности на сжатие брикетов со связующим из древесных опилок от влажности бурого угля: 1 - прочность через 4 ч; 2 - прочность через 24 ч 
В этой связи дальнейшие исследования по брикетированию березовского бурого угля были направлены на снижение содержания древесных опилок в шихте для брикетирования путем частичной замены опилок на биообработанный бурый уголь (биоуголь).

Изучение влияния влажности биоуглей на прочностные характеристики получаемых из них брикетов показало, что в зависимости от применяемого давления прессования значение влажности, соответствующее максимальной прочности получаемых брикетов, снижается с 16,8 до 15,6 \% при увеличении давления прессования со 100 до 140 МПа (рис. 3). При этом прочность на сжатие получаемых брикетов возрастает с 20,2 до 30,6 МПа соответственно.

Полученные данные о прочностных характеристиках брикетов из биоуглей свидетельствуют о том, что в процессе аэробной биообработки значительно возрастают пластические свойства бурого угля. Брикетирование исходного бурого угля в аналогичных условиях не позволяет получать брикеты удовлетворительного качества (прочность на сжатие не менее 7-9 МПа).

Целью исследования связующих свойств биоуглей, как и в случае с древесными опилками, являлось нахождение оптимальной влажности исходного и биообработанных углей, при которых получаемые брикеты обладают максимальной прочностью.

Как следует из приведенных на рис. 4 данных, при введении в качестве связующего биоуглей в количестве 30 мас. \% максимальную прочность имеют брикеты, полученные из угля с влажностью 17,0, 16,2 и 15,1 \% при давлениях прессования 100, 120 и 140 МПа соответственно.

Испытание прочности получаемых брикетов через 24 ч после прессования выявило незначительное (на 0,5-0,8 МПа) уменьшение их прочности на сжатие. Из анализа полученных зависимостей можно сделать вывод о том, что при увеличении давления прессования происходит увеличение прочности брикетов со сдвигом оптимума влажности брикетируемого угля в область пониженных значений.

Изучение влияния бинарных составов связующих на прочностные свойства брикетов проводили с шихтой, содержащей 60 мас. \% березовского угля и 40 мас. \% бинарного связующего, состоящего из опилок и биоугля.

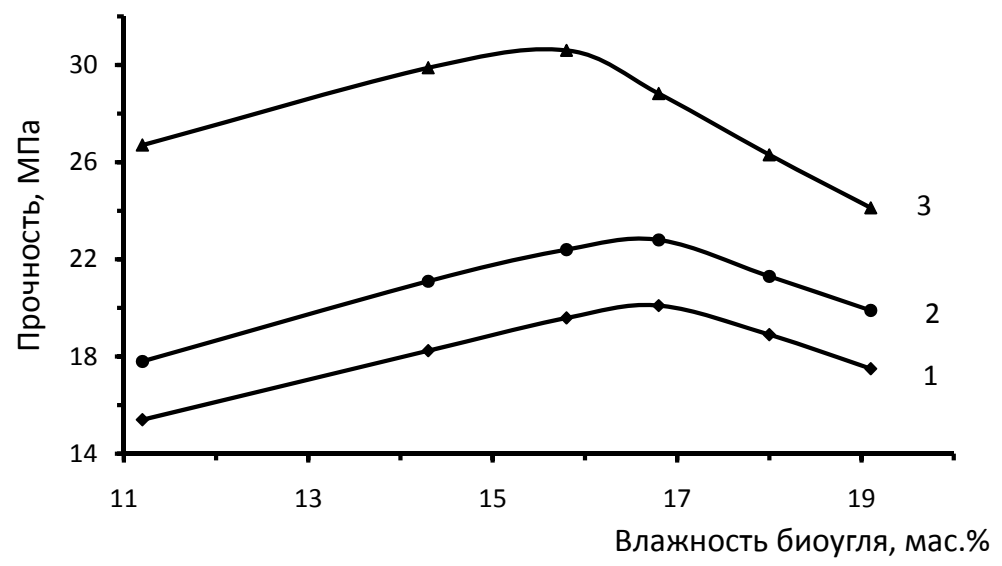

Рис. 3. Зависимость прочности на сжатие брикетов из биоугля от влажности при давлениях прессования, МПа: $1-100 ; 2-120 ; 3-140$ 


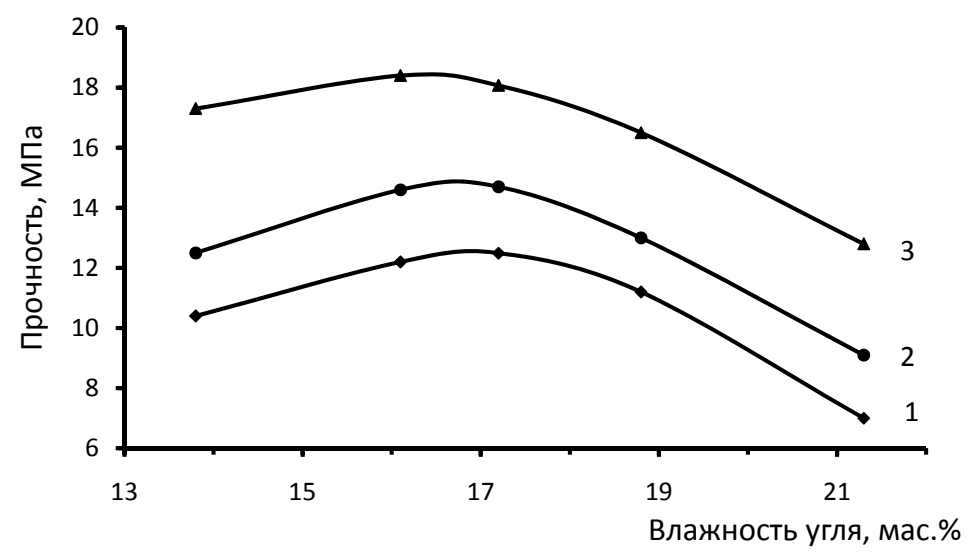

Рис. 4. Зависимость прочности брикетов на сжатие от влажности угля (содержание биоугля - 30 \%) при давлениях прессования, МПа: 1 - 100; 2 - 120; 3 - 140

Установлено, что варьирование состава бинарного связующего позволяет получать прочные брикеты. При этом повышение удельного давления прессования способствует увеличению прочностных свойств брикетов.

Так, например, увеличение давления прессования со 100 до 140 МПа при введении связующего, содержащего 50 \% опилок и 50 \% биоугля, увеличивает прочность брикетов с 18,5 до 26,2 МПа (рис. 5). При введении в состав связующего биоугля в количестве 75 мас. \% прочность брикетов повышается от 14,5 до 22,3 МПа соответственно. Это позволяет говорить о возможности уменьшения количества древесных опилок, используемых в качестве связующего при брикетировании бурого угля.

Приведенные в табл. 2 характеристики брикетов из березовского бурого угля, полученных с использованием в качестве связующих древесных опилок, биоуглей и их смеси, показывают, что теплота сгорания и продолжительность процесса горения брикетов возрастают при увеличении содержания биоугля в брикетируемой шихте.

Термическая устойчивость брикетов, характеризующая прочность брикетов при слоевом сжигании, увеличивается с 19 мин для брикетов, полученных из древесных опилок, до 30 мин для брикетов, полученных из чистого биоугля. При этом максимальную рабочую теплоту сгорания (4538 ккал/кг) имеют брикеты, полученные при использовании в качестве связующего биоугля.

\section{Заключение}

На основании проведенных исследований было установлено, что использование в качестве связующих древесных отходов, продуктов аэробной биотехнологической переработки бурых углей и их смесей в количестве 30-40 отн. \% позволяет получать прочные высококалорийные топливные брикеты из буроугольных отсевов при удельных давлениях прессования 100-140 МПа.

Показано, что полученные топливные брикеты имеют прочность выше нормируемых показателей и обладают высокой устойчивостью при сжигании.

$$
-436-
$$




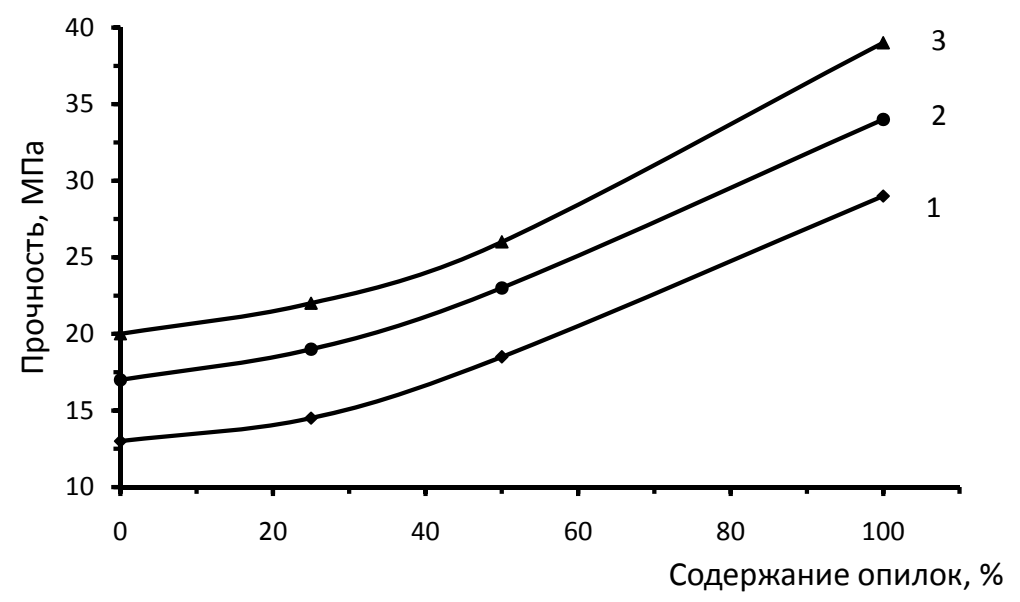

Рис. 5. Зависимость прочности брикетов на сжатие от содержания опилок в бинарном связующем и давления прессования, МПа: 1 - 100; 2 - 120; 3 - 140

Таблица 2. Характеристики брикетов из бурого угля, полученных с использованием в качестве связующих древесных опилок, биообработанных углей и их смеси

\begin{tabular}{|c|c|c|c|c|c|}
\hline $\begin{array}{l}\text { №, } \\
\text { П/ח }\end{array}$ & $\begin{array}{c}\text { Состав шихты, } \\
\text { мас. } \%\end{array}$ & $\begin{array}{c}\text { Давление } \\
\text { прессования, } \\
\text { МПа }\end{array}$ & $\begin{array}{c}\text { Прочность на } \\
\text { сжатие, МПа }\end{array}$ & $\begin{array}{c}\text { Устойчивость } \\
\text { при сжигании, } \\
\text { мин }\end{array}$ & $\begin{array}{c}\text { Теплота } \\
\text { сгорания, } \\
\text { Qr, ккал/кг }\end{array}$ \\
\hline 1 & Биоуголь & 120 & 28,8 & 30 & 4490 \\
\hline 2 & Опилки & 100 & 43,1 & 18 & 3720 \\
\hline 3 & $\begin{array}{l}\text { Уголь }-60 \\
\text { Опилки }-40\end{array}$ & 100 & 33,5 & 19 & 4215 \\
\hline 4 & $\begin{array}{l}\text { Уголь - } 70 \\
\text { Биоуголь }-30 \\
\end{array}$ & 120 & 20,3 & 27 & 4538 \\
\hline 5 & $\begin{array}{l}\text { Уголь }-60 \\
\text { Биоуголь }-30 \\
\text { Опилки }-10\end{array}$ & 120 & 22,8 & 24 & 4326 \\
\hline
\end{tabular}

Установлено, что максимальную теплоту сгорания (4538 ккал/кг) имеют брикеты, полученные при использовании в качестве связующего чистого биоугля.

\section{Список литературы}

1. Белосельский Б.С. Барышев В.И. Низкосортные энергетические топлива. М.: Энергоатомиздат, 1989. $136 \mathrm{c.}$

2. Тайц Е.М., Равич Б.М., Андреева И.А. Получение окускованного бездымного топлива и кокса. М.: Недра, 1970. С. 97-98.

3. Тайц Е.М., Андреева И.А., Антонова Л.И. Брикетирование углей Б2 // Окускованное топливо и адсорбенты на основе бурых углей. М.: Недра, 1985. С. 72-80.

4. Гудкова Е.А. Стратегия энергосбережения и повышения экологической безопасности регионов в фокусе перспективы использования пеллетного топлива // Строительство: 
наука и образование. 2012. № 3. С. 4. [Электронный ресурс] Режим доступа: http://www. nso-journal.ru.

5. Иванов И.П., Головин Ю.Г., Кузнецов Б.Н. Использование продуктов аэробной биопереработки бородинского бурого угля для получения брикетированного топлива // Химия твердого топлива. 1999. № 3. С. 113-118.

6. Иванов И.П., Судакова И.Г. Брикетированные и бездымные топлива, получаемые из бурого угля с использованием биосвязующих // Наука - производству. 2003. №1. С. 28-29.

7. Иванов И.П. Особенности процесса аэробной биопереработки бурых углей // Химия твердого топлива. 2007. №2. С. 15-19.

8. Иванов И.П., Теремова М.И., Еремина А.О. Аэробная переработка бурого угля штаммом Acinetobacter calcoaceticus.// Journal of Siberian Federal University. Chemistry. 2014. T.7. № 2. C. 209-220.

9. Тайц Е.М., Андреева И.А. Методы анализа и испытания углей. М.: Недра, 1983. С. $203-$ 205.

10. Кривовяз И.М. Процессы образования прочных углеродистых материалов. Ташкент.: Фан, УзССР, 1970. С. 35-51.

11. Химическая технология твердых горючих ископаемых / под ред. Г.Н. Макарова, Г.Д Харламповича. М.: Химия, 1986. 435 с. 